Perspective

\title{
Perspectives for the development of energy strategies - Challenges towards a hydrogen economy in Cyprus
}

Andreas Poullikkas

Received: 12 Jan 2021

Accepted: 9 Apr 2021

Published: 5 Oct 2021

\section{Copyright:}

(C) 2021 by the author(s). This is an Open Access article distributed under the terms of the Creative

Commons License

Attribution 4.0

International (CC BY 4.0), which permits unrestricted use, distribution, and reproduction in any medium or format, provided the original work is correctly credited.

\section{Publisher's Note:}

Pivot Science Publication Corp. remains neutral with regard to jurisdictional claims in published maps and institutional affiliations.
Cyprus Energy Regulatory Authority, P.O. Box 24936, 1305 Nicosia, Cyprus;

E-Mail: andreas.poullikkas@eecei.cut.ac.cy; Tel.: +35722666363;

Fax: +35722667763

\begin{abstract}
The present perspective aims to record the main actions that Cyprus, as a case study, needs to carry out in order to draw up a comprehensive long-term sustainable energy strategy for its transition from carbon economy to hydrogen economy. A brief description of the European sustainable energy strategy up to 2050 is provided. A transition to hydrogen economy by 2050, focusing on the importance of electricity interconnections including Cyprus' crucial role with respect to the transition of Southeastern Mediterranean countries to hydrogen economy and how they could become energy exporters to Europe is discussed. Last but not least, this perspective presents the framework for drafting a long-term energy strategy for Cyprus and provides a set of targets for Cyprus' energy transition to hydrogen economy by the year 2050
\end{abstract}

Keywords: energy transition; hydrogen economy; energy policy; energy systems; sustainable energy strategy

\section{Introduction}

The EU has drawn up a sustainable energy strategy in order to confront climate change and boost energy security [1]. The package of proposals sets out a number of ambitious objectives for the reduction of greenhouse gas emissions and the use of renewable energy sources. The ultimate goal is to turn the existing EU energy system into a sustainable, technologically advanced and smart system.

Cyprus although an EU Member State is a country with many particularities. For instance, it is isolated from the rest of Europe and its economy is based on tourism. Cyprus' economy is dependent on oil and is often affected by severe water shortages [2]. At the same time, however, Cyprus has high potential 
regarding renewable energy sources. In particular, Cyprus can easily exploit solar energy and, also, possesses potential reserves of natural gas $[3,4]$. Thus, Cyprus with proper planning will be able to invest in new sustainable technologies, to manage its energy resources and needs in an optimal way, to reduce their environmental impact and to ensure its future energy security [5-8]. The policies to be developed must arise through consultation and meet acceptance by the State so that they can be agreed upon by all parliamentary parties and relevant State entities. This will ensure continuity and consistency in Cyprus' energy strategy.

The present perspective aims to record the main actions that Cyprus, as a case study, needs to carry out in order to draw up a comprehensive long-term sustainable energy strategy for its transition from carbon economy to hydrogen economy. Section 2 provides a brief description of the European sustainable energy strategy up to 2050 and section 3 describes Cyprus' transition to the hydrogen economy by 2050 . Section 4 refers to the importance of electricity interconnections and discusses Cyprus' crucial role in this aspect and section 5 provides the framework with respect to the transition of Southeastern Mediterranean countries to the hydrogen economy and how they could become energy exporters to Europe. Section 6 provides the for the development of a sustainable energy strategy and finally, section 7 summarises all of the above issues, whilst also, providing a set of targets for Cyprus' energy transition to hydrogen economy by the year 2050.

\section{Future European Energy System}

A descriptive analysis of an optimistic scenario, based on the EU's long-term energy targets regarding the transition of EU from carbon economy to hydrogen economy is presented in Figures 1-3, [1]. EU's current energy system is shown in Figure 1, in which black lines denote flow of oil, green lines denote flow of natural gas and blue lines denote flow of electricity. Oil holds a significant position as it is widely used in the industrial, domestic and transportation sector. Moreover, natural gas is used in all sectors as well as for electricity generation, along with coal and nuclear energy.

Between years 2020-2030, the use of oil will be limited to cover the needs of the transport sector only as shown in Figure 2. Natural gas will play a protagonist role in all areas as a transitional fuel towards hydrogen economy $[9,10]$. Furthermore, part of the natural gas will be reformed in order to produce hydrogen, which is an environmentally friendly fuel, without 
any harmful emissions $[11,12]$. In addition, the first hydrogen communities will begin to form producing green hydrogen, that is, hydrogen from distributed renewable energy systems.

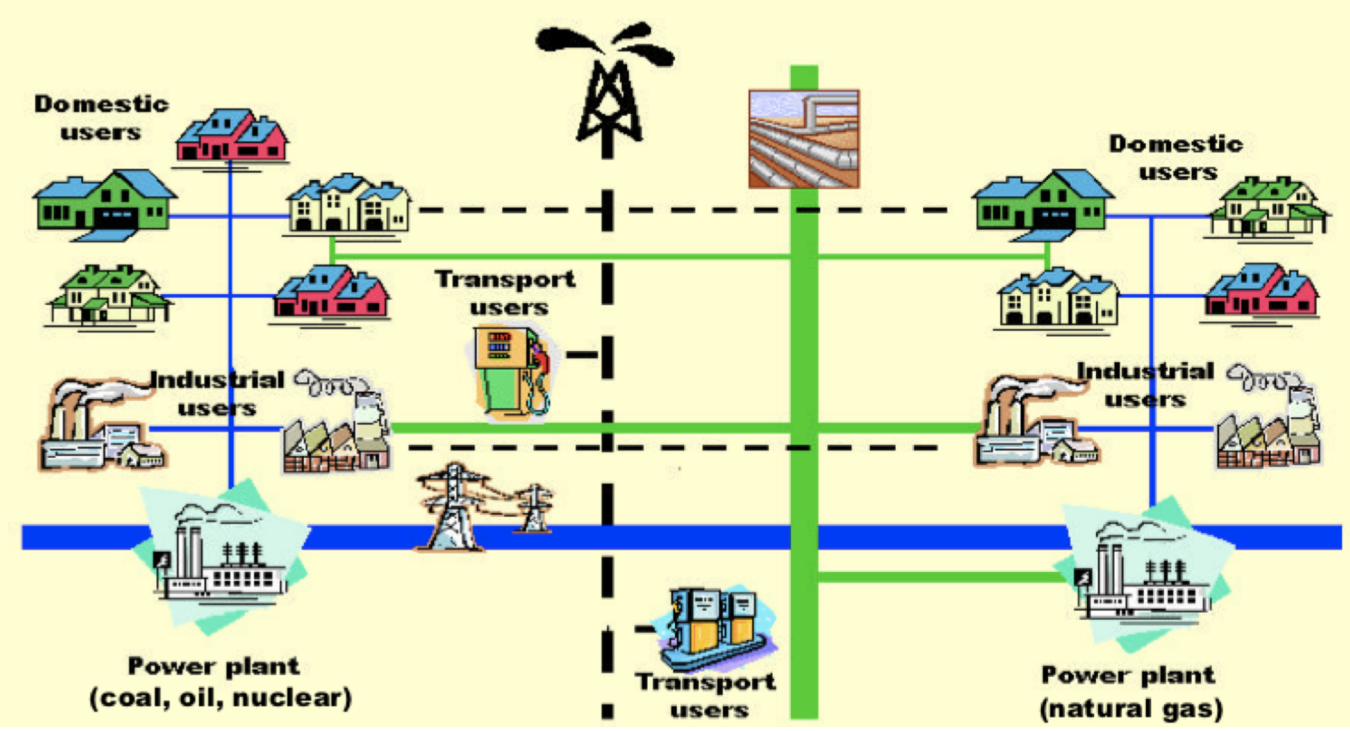

Figure 1 Current EU energy system [1].

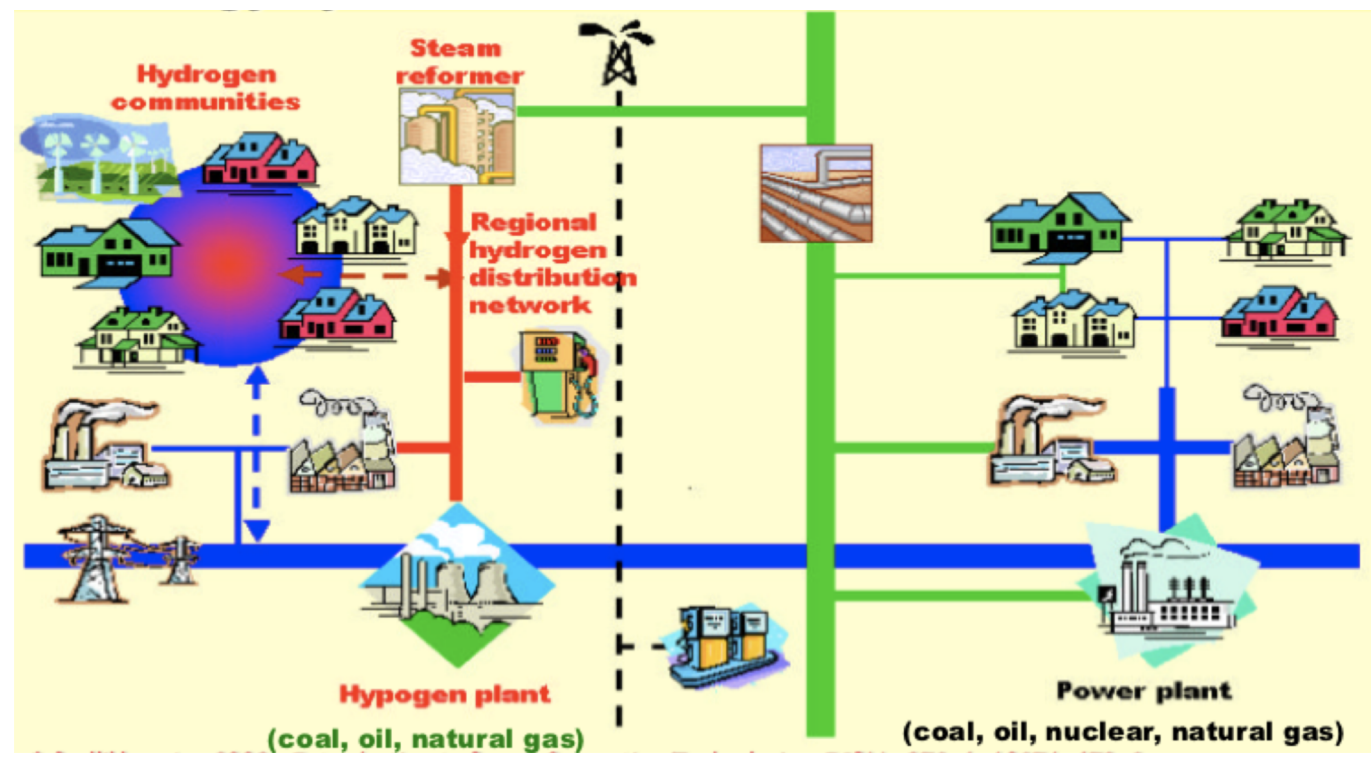

Figure 2 EU energy system between 2020-2030, optimistic scenario of the transition to hydrogen economy [1]. 


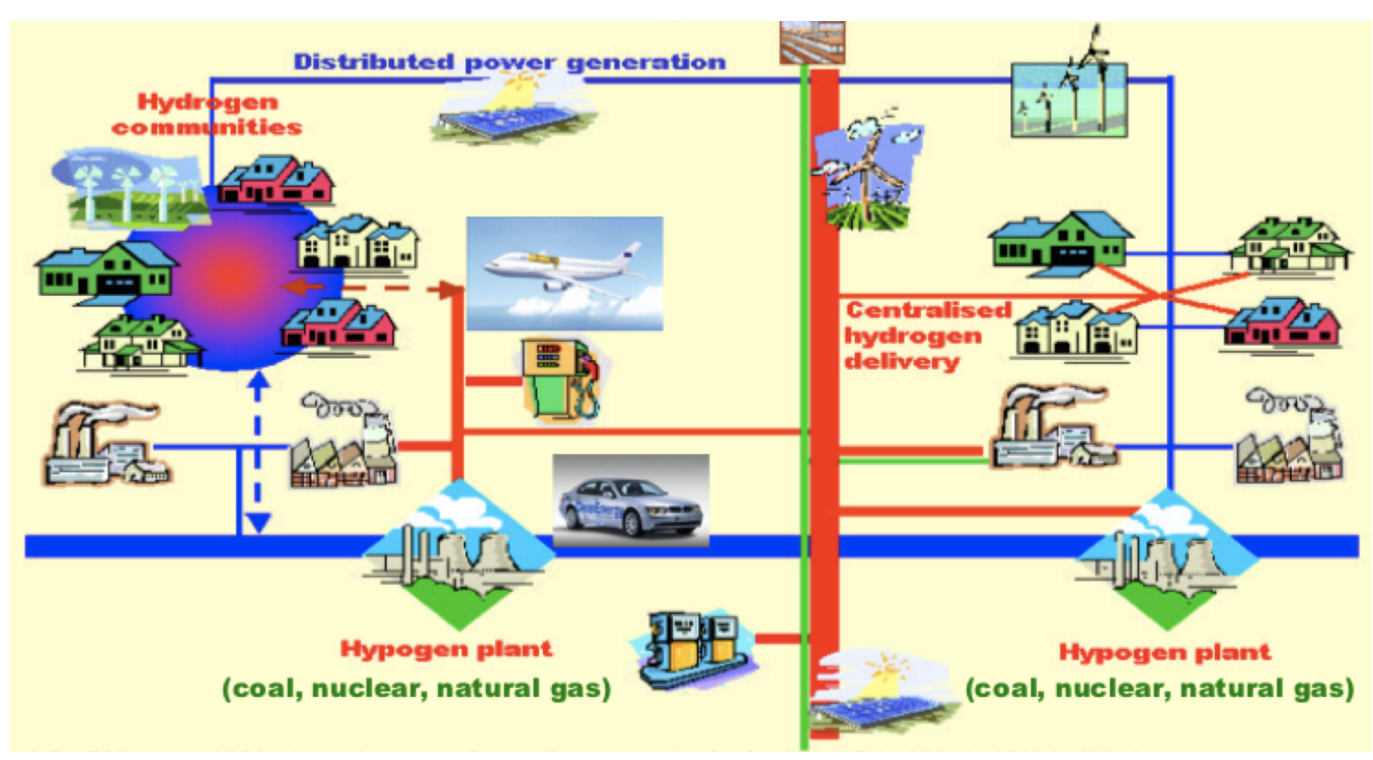

Figure 3 EU energy system between 2040-2050, optimistic scenario of the transition to hydrogen economy [1].

The first hydrogen power generation (Hypogen) systems will be commercially available, intended to cover part of the electricity demand with zero industrial emissions and zero carbon dioxide emissions [13]. Between 2040 and 2050, Figure 3, oil will no longer be used, since it is expected that hydrogen will be used on a large scale, which will be produced either from natural gas reforming or from coal gasification or from renewable energy sources. By then, the EU will have converted its current economy to hydrogen economy.

On the left hand side of Figure 4 the current arrangement for generation, transmission and distribution of electricity is illustrated [14]. Today, electricity is mainly generated centrally at large power stations and is delivered to consumers through the transmission and distribution systems. EU has set long-term goals for the future electricity system, which is expected to take into account environmental and economic factors in addition to security of supply. This is shown diagrammatically on the right hand side of Figure 4.

The future electricity system will consist of central power plants with clean and environmentally friendly technologies such as carbon capture and storage (CCS) systems in the first case, which will produce the basic load, along with nuclear power plants [15]. At the same time, in the electricity network, there will also be integrated (on a large scale) renewable energy sources (RES) such as wind and photovoltaics as well as distributed generation (DG) systems [16]. Moreover, it is expected that storage systems will be developed such as batteries as well as production and storage of hydrogen and its use 
for electricity generation when needed. For example, during the night when the load demand is low, currently due to technical problems some wind farms cannot be dispatch to the electrical system [17].

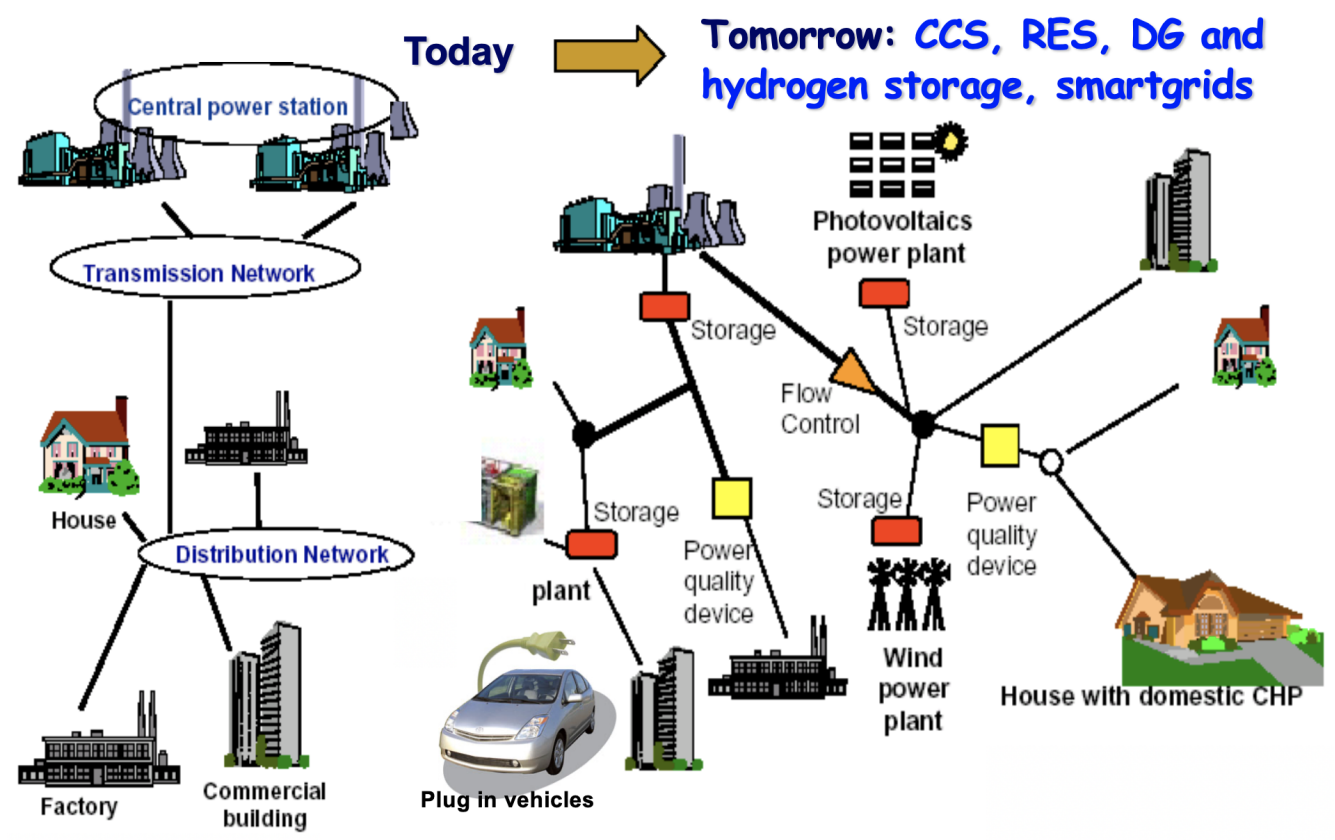

Figure 4 Future electricity system [14].

However, in the future, with the use of storage devices, dispatching of wind farms can be feasible, whenever wind potential is available. In case when wind farms cannot inject directly the generated electricity into the system (e.g., due to low load demand), green hydrogen can be produced by water electrolysis [18]. Green hydrogen can be stored and used during the day in order to meet peak demand or in other energy sectors such as transportation. Central power plants will be producing at their maximum capacity (hence at maximum efficiency), 24 hours a day [19]. The surplus electricity can be used, as in the case of renewable energy sources, for the production of hydrogen by electrolysis of water. As before, hydrogen can be stored and used during the day in order to meet peak demand or in other energy sectors such as transportation [20].

Finally, by 2050, the installation and use of the super smartgrid is expected, as shown in Figure 5 . Renewable energy sources will be installed on a large scale in areas with high potential including biomass (B) systems and hydropower (H) systems [21]. For example, it is possible for wind farms to be installed in the North Sea and on the west coast of Europe and North Africa. Solar systems (photovoltaic and solar thermal) can be installed in Southern Europe, in North Africa and the Middle East. Wave (M) energy technologies [22] can 
be installed in the Atlantic Ocean and geothermal (G) technologies in Iceland. With this geographical distribution of renewable energy sources as well as the production of green hydrogen and use of storage (S) technologies, it will be possible to use $100 \%$ renewable energy sources in the future [23].

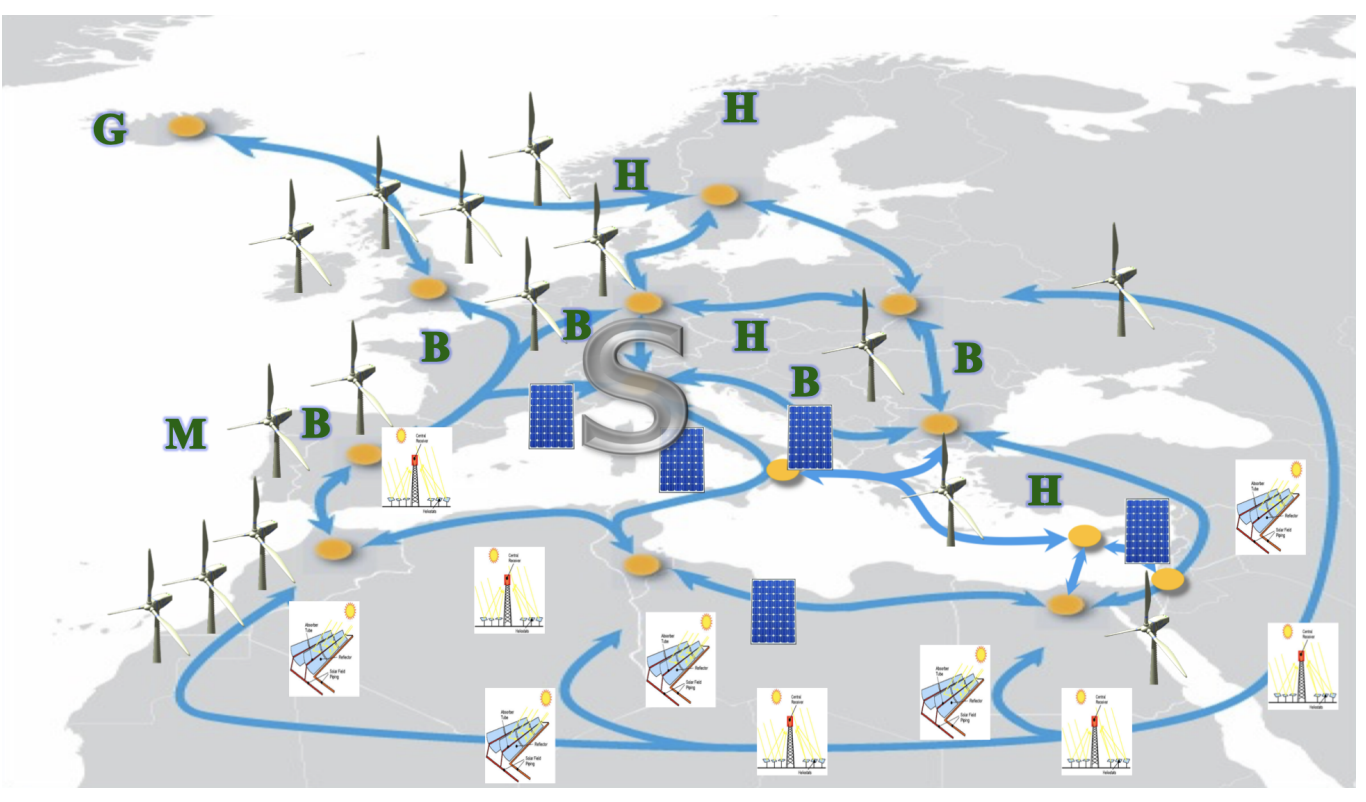

Figure 5 Future super smartgrid [14].

\section{Energy Transition}

Cyprus has a strong incentive to proceed with energy transition due to the high degree of dependence on oil imports which make the country vulnerable to any reduction in oil stocks as well as to any increase in oil price [4]. The implementation of the Cyprus energy transition will require significant energy investments over the next 30-40 years. To achieve this transformation of the energy sector, an ambitious, long-term integrated energy strategy is required in order to set clear goals and create the appropriate reliable and coherent regulatory framework. For example, Cyprus could draw up its energy strategy in such a way as to become a center for the development of a low carbon dioxide emissions economy and of hydrogen economy [24, 25]. In this way, sustainable technologies that could be developed and tested in the small energy system of Cyprus, could then be transferred on a larger scale to other EU Member States as well as to the rest of the world. 
With a proper plan, Cyprus could be transformed into a green country model by 2050 [26]. Given the fact that Cyprus will be able to extract its own gas reserves and perhaps oil reserves, it would be possible from today to develop a long-term energy strategy. Referring to Figure 6 natural gas and oil will reach the land, where part of these quantities could be traded to the international market. The rest of the quantities, in the case of natural gas, could be reformed to produce hydrogen and in the case of oil could be gasified to produce hydrogen [4]. The carbon dioxide produced by reforming and gasification could be directed into the oil well for storage, whilst at the same time, also, helping in the extraction of oil (enhanced oil recovery). Large scale installation of renewable energy sources together with the hydrogen storage systems could be used for green hydrogen production and hydrogen will be used for electricity generation, for transportation, as an industrial fuel and in the domestic sector with the development of a distribution network, with emissions being only water vapour $[27,28]$. The rest of the hydrogen would be available for trading in the international market.

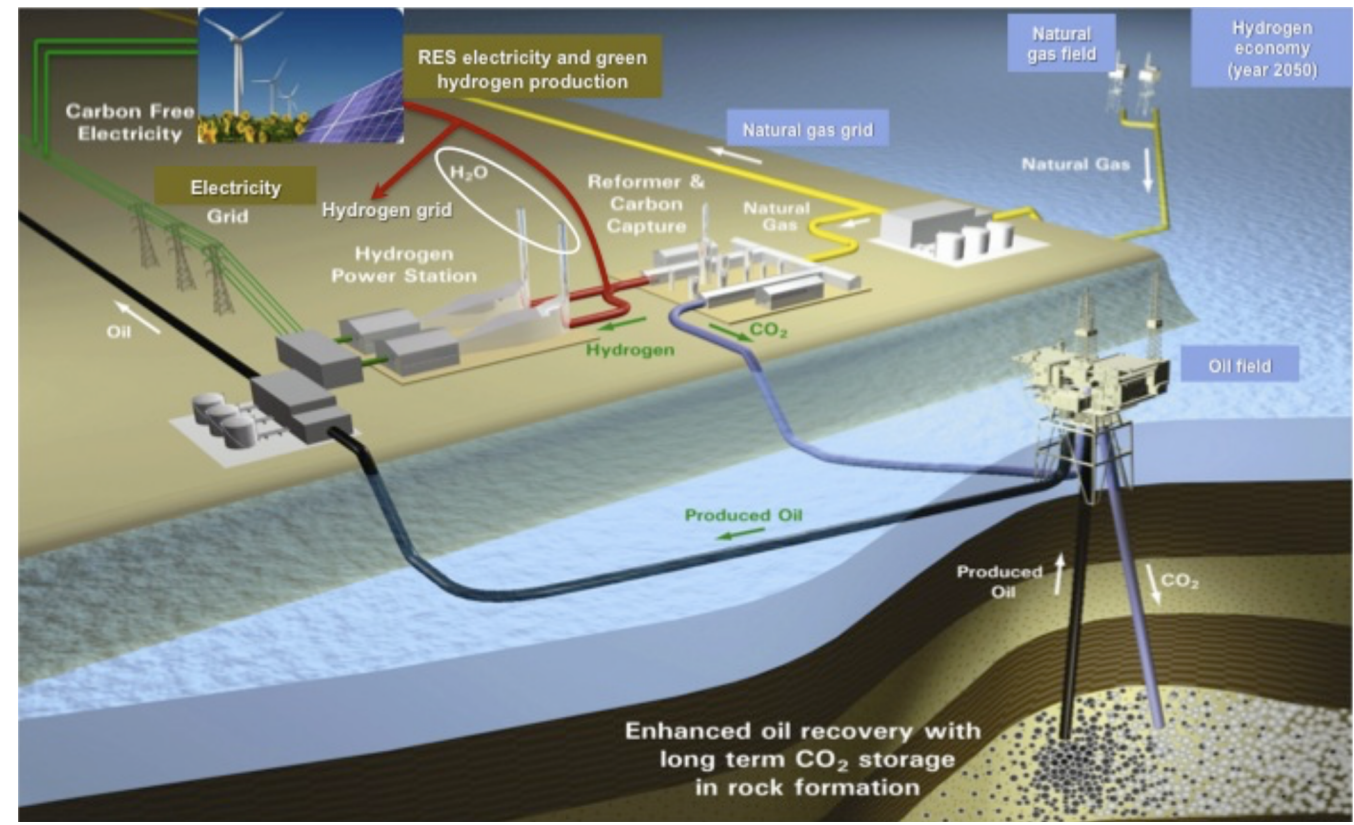

Figure 6 Transition of Cyprus to low carbon emissions and hydrogen economy by 2050 [14].

\section{Electricity Interconnections}

The need for regional cooperation in the electricity sector not only between EU countries but, also, in the wider region, is one of the highest energy priorities with key components at the political, economic and geo-strategic level [1]. Electricity interconnections are primarily aimed at improving energy 
security and reliability, allowing the introduction or exchange of electricity from neighbouring systems. In addition, the electricity interconnections are very important for the achievement of the EU's goal for a single internal electricity market and the facilitation of the integration of significant amounts of energy from renewable sources planned throughout the EU [4].

Cyprus' energy resources present a combination of the potential deposits of hydrocarbons and renewable energy sources (e.g., solar energy). This combination is the comparative advantage of Cyprus in the energy sector which must be taken into account in the context of the current cross-border infrastructure and electricity interconnections and the development of alternative routes for EU energy supplies [7]. As energy networks, especially electricity, grow rapidly across the EU serving the ever-increasing needs for electricity, the need to connect Cyprus with its wider geographical area is obvious. The development of significant energy infrastructure elements, especially electricity interconnections, should be an important catalyst in the implementation of Cyprus' strategy, not only as part of the EU's target for electricity interconnections between Member States but, also, as a national political priority. This will help in the strengthening and tightening of diplomatic relations as well as in the creation of new investment and economic opportunities [14].

Electricity interconnections constitute an excellent opportunity for greater flexibility of Cyprus' business activities, creating the right ground for new investment opportunities either in electricity generation or in industry and other sectors. The main actors involved in such collaborations are the local and regional authorities, the chambers of commerce, the state, the business community and citizens generally, all of which are motivated by mutual benefit. Furthermore, some of the most important economic benefits that will be created by the implementation of electricity interconnections are the significant inflows of foreign direct investment as a result of the construction of a capable electricity network that will be able to transfer electricity generated in Cyprus by new renewable energy and natural gas power stations.

In this way, energy cost will be reduced with the utilisation of renewable energy sources in areas with high potential and lower production costs, thus improving the reliability and economic value of the system. In addition this can, also, contribute to better utilisation and management of the renewable energy potential in Cyprus. Such penetration of renewable energy sources will, in fact, require the construction of high power capacity and long distance 
electricity interconnections for the transportation of electricity but, also, for the competitive electricity market [4].

Cyprus, acting in accordance with the right planning, can make the most of its energy potential, thus being transformed into a producer-state and exporting electricity using appropriate electricity interconnections, such as the EuroAsia Interconnector and EuroAfrica Interconnector, so as to escape from its energy isolation. This would allow Cyprus to become a hub for electricity transfer to and from the EU and to and from Israel and Egypt, while increasing at the same time our energy security.

\section{Hydrogen Economy}

It is expected that in the future the hydrogen economy will greatly contribute to the exploitation of renewable and environmentally friendly energy sources and the development of similar new technologies. The term "hydrogen economy" refers to the infrastructure meeting the energy needs of a future hydrogenbased society [29-31]. It, also, encompasses the concepts of the production, distribution, storage and use of hydrogen as presented in Figure 7. In addition, if the production of hydrogen is based on renewable energy sources, the above processes constitute parts of a clean, environmentally friendly, circular process, the so-called hydrogen cycle [18,32].

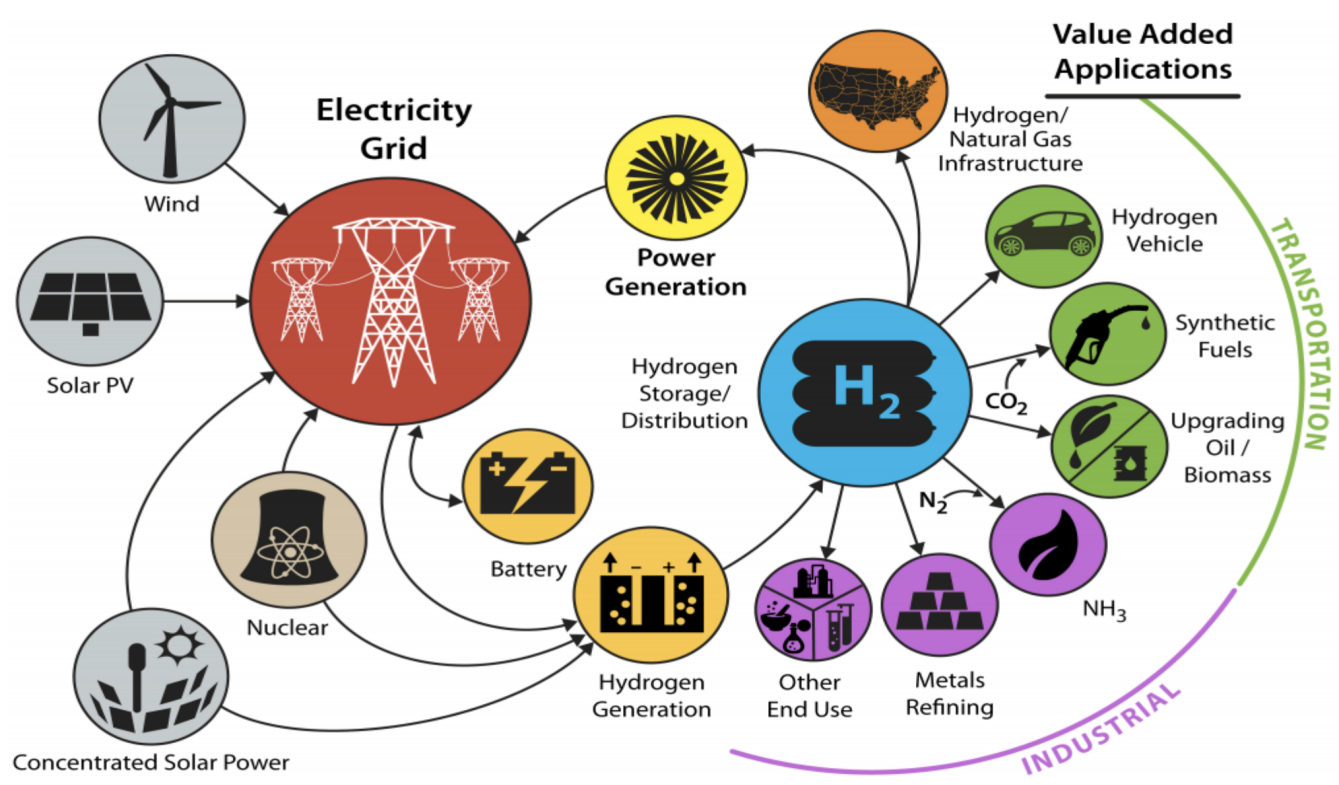

Figure 7 Transition from carbon economy to hydrogen economy. 
Hydrogen offers the opportunity to solve the problems of energy supply, climate change and air pollution that countries are facing. For the production of energy, hydrogen and oxygen are used with the only waste being water and heat [33]. Oxygen is abundant in the atmosphere, while hydrogen can be extracted from hydrocarbons, such as through natural gas reforming, but with the release of significant amounts of carbon dioxide emissions [34,35]. Alternatively, it can be extracted through water with the process of electrolysis, or by using solar energy through a thermochemical splitting of water into oxygen and hydrogen $[5,10,11]$.

Given the existence of hydrocarbons in the Southeastern Mediterranean, as well as the strong interest in investing in renewable energy sources, the Southeastern Mediterranean countries should move towards energy sustainable development by combining proper management of hydrocarbons with sustainable growth for the benefit of future generations. That is to say the transformation of the existing polluting energy system of Cyprus but, also, of the countries of the Southeastern Mediterranean into a sustainable energy system based on differentiated energy sources of higher energy efficiency with a long-term goal of turning the economy into a hydrogen economy to enhance cooperation and prosperity.

This could be achieved by drawing up a common long-term strategic plan with a horizon beyond 2050. The strategy will take into account, among other things: (a) the interconnection of the Southeast Mediterranean countries with European countries through electrical cables, (b) the interconnection of the Southeastern Mediterranean countries with European countries through natural gas pipelines and/or virtual natural gas pipelines, (c) the integration of sustainable energy technologies in all countries of the Southeastern Mediterranean, (d) the use of hydrogen after 2030 produced from renewable energy sources and from natural gas reforming, (e) the export of electricity to European countries and (f) the export of hydrogen to European countries. The countries of the Southeast Mediterranean region can become pioneers towards hydrogen economy and become exporters of sustainable energy to the EU.

\section{Steps for the Development of a Sustainable Energy Strategy}

The steps needed to be taken to develop a comprehensive, targeted, long-term sustainable energy strategy for Cyprus are provided below:

Development of activities in the area of energy efficiency, such as: 
(i) increasing consumers' awareness with the supply of educational materials and educational advertisements so as to cultivate energy awareness in terms of energy efficiency, energy saving and energy management,

(ii) continuing the development and implementation of sustainable methods and standards in the optimal analysis of the life cycle of each product or process,

(iii) developing the appropriate structures and continuing to inform consumers about the existing programs and studies on energy saving,

(iv) using efficient electric mobility technologies in the transport sector,

(v) developing new processes that will improve productivity, product quality and energy use, and

(vi) reducing energy losses further, improving the design of the future power system and increasing the efficiency of generation, transmission and distribution systems.

Development of strategies related to the use of alternative fuels and the electrification of the transport sector, including the public transport sector, such as:

(i) the use of sustainable biomass for conversion to biofuels that will be able to be mixed and distributed along with petrol,

(ii) the promotion of biofuel usage containing high energy efficiency,

(iii) the promotion of natural gas usage in the transport sector,

(iv) the increase of efficiency in transportation and promotion of the development of the use of hybrid and electric cars,

(v) the promotion of electric car charging points in cities and highways,

(vi) the integration of electric vehicles into the electrical system with the development of flexible tariffs and standards, and

(vii) the assessment of actual costs or benefits and the advantages that lie ahead for public health from the use of alternative fuels and from the electrification of the transport sector.

Development of strategies related to the use of renewable energy sources for electricity generation, such as:

(i) the promotion of renewable energy sources usage, since they offer energy safety and no greenhouse gas emissions,

(ii) the transformation of the current transmission and distribution network with a smart network to support increased penetration of renewable 
energy sources for electricity generation, storage systems and electric cars,

(iii) the continuous development of the power system including electricity interconnections with other States and the use of storage systems, so as to achieve further penetration of intermittent renewable energy sources for electricity generation, for the benefit of society, and

(iv) the continuous review of electricity market rules in order to achieve large scale penetration of electricity renewable energy sources in connection with the use of electricity interconnections and energy storage systems.

Development of strategies for the use of renewable energy sources, e.g., solar energy and geothermal energy, in heating and cooling sector, such as:

(i) the development of a stable and predictable investment environment, since uncertainty increases risk and therefore the cost of these investments, the returns of which should be commercially competitive with corresponding investments in technologies related to energy resources,

(ii) the continuous and adequate training of plumbers and installers for the successful installation of heating and cooling technologies from renewable energy sources, since in order to achieve high quality facilities, information and training programs are needed, and

(iii) the launch of a process ensuring standards for the application of various heating and cooling technologies from renewable energy sources.

The Cypriot hydrocarbon development model should go hand in hand with the Norwegian model and create similar structures and activities, that is:

(i) as in the case of Norway, oil resources belong to Cypriot people and should be managed in a way that benefits the whole of Cypriot society,

(ii) it is necessary to encode the Cypriot ten commandments relating to hydrocarbons,

(iii) creating a fund for the management of revenues from indigenous hydrocarbon reserves in a reliable and transparent manner, while ensuring safeguards for continuous control (the fund should be the key element of social solidarity, which will support for decades the social security system of Cyprus and at the same will time give a huge geo-economic boost and upgrade to our country, through the solution of basic problems of the national economy), and 
(iv) utilisation of Cyprus's hydrocarbon deposits in the form of sustainable development.

Given the above steps needed in order to draw up a comprehensive sustainable energy strategy for Cyprus's energy transition, it is necessary for Cyprus to develop immediately a long-term sustainable development strategy. The following steps need to be taken:

(i) Calculation of future greenhouse gas emissions per sector based on the business as usual scenario in order to give a better understanding of the scenarios and the actions that should be developed to reduce emissions.

(ii) Calculation of greenhouse gas emissions based on the various scenarios related to emission reduction actions compared to 1990 (for each action, the cost or benefit that arises should be estimated and compared to the business as usual scenario beyond the year 2050 in order to draw the strategy to be followed and to set the objectives).

(iii) For the sectors of transport, electricity generation and penetration of renewable energy sources, the development of a study with a time horizon beyond the year 2050 so as to calculate the optimal energy mix per sector (examination of various scenarios starting with the business as usual scenario followed with other scenarios such as penetration rates of renewable energy sources and percentages of penetration of electric cars and alternative, non-conventional fuels, such as hydrogen).

(iv) For each scenario, specified in point (iii) above, an estimate must be made of the resulting cost, comparing it to the business as usual scenario in order to provide a clear understanding of the resulting economic aspects.

\section{Energy Targeting for Cyprus}

Cyprus could set a long-term goal of reducing greenhouse gas emissions by $100 \%$ by 2050 [4]. Table 1 provides indicative targets for achieving the aforementioned reduction with intermediate targets for the use of renewable energy sources and electrical interconnections of Cyprus with the EU's internal electricity market. The optimistic targets set for the decades 2021-30 and 2031-40 can be achieved with proper planning and proper monitoring with the implementation of inter-party energy strategy agreements in Cyprus.

The final goal is the transition of Cyprus from the current carbon economy to a hydrogen economy by the year 2050, as already illustrated in Figure 6 . 
Refering to Figure 8, by the year 2050, Cyprus' energy system will become smart and digitised, flexible, decentralised, electrically interconnected and interconnected with pipelines and/or virtual gas and/or hydrogen pipelines, where the use of (a) hydrogen in all energy fields, (b) renewable energy sources, (c) storage energy systems and (d) electric mobility, will take place.

Table 1 Target-setting for Cyprus' transition to hydrogen economy.

\begin{tabular}{lccc}
\hline Goal description & & Year & \\
& $\mathbf{2 0 3 0}$ & $\mathbf{2 0 4 0}$ & $\mathbf{2 0 5 0}$ \\
\hline Greenhouse gases ${ }^{a}$ & $-30 \%$ & $-75 \%$ & $-100 \%$ \\
Renewable energy sources & $30 \%$ & $75 \%$ & $100 \%$ \\
Electrical interconnections & $50 \%$ & $65 \%$ & $80 \%$ \\
\hline
\end{tabular}

${ }^{a}$ Reduction in relation to the reference year 2005.

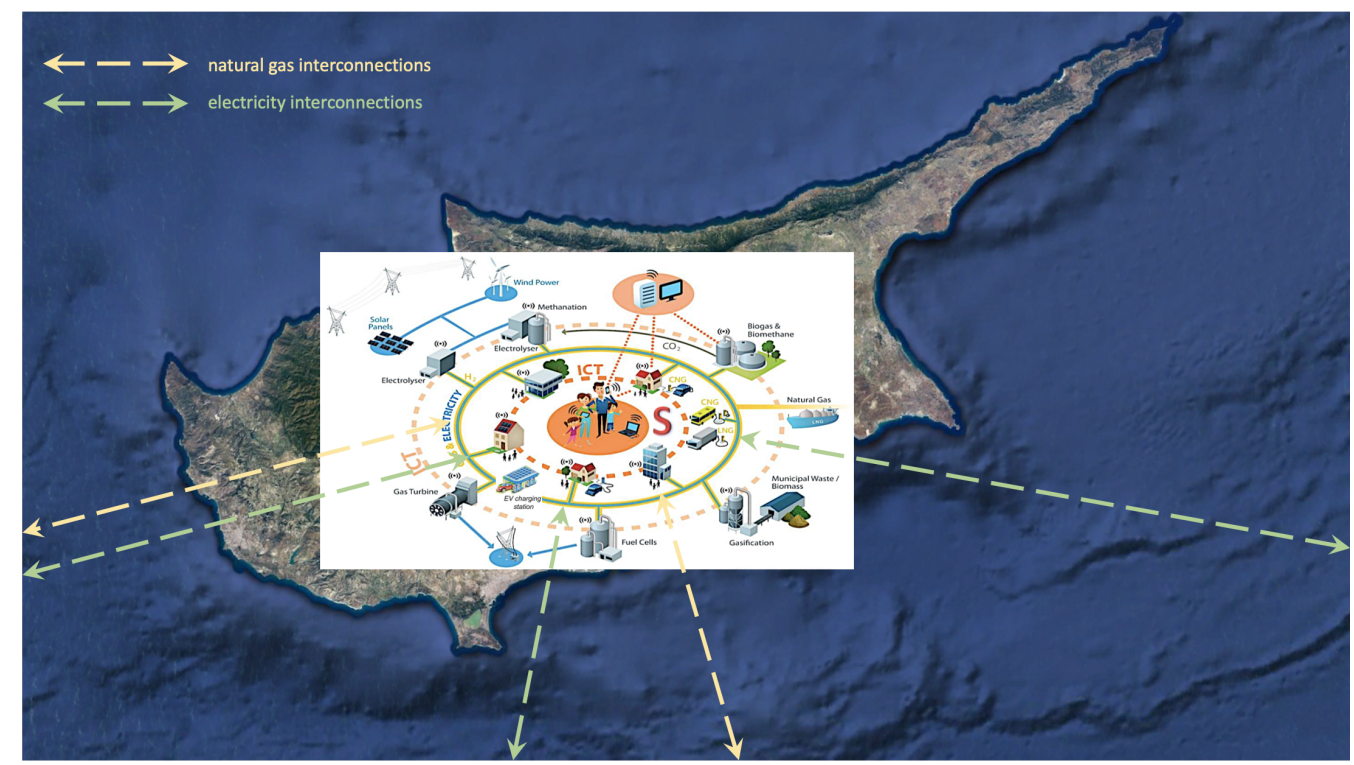

Figure 8 Energy Transition of Cyprus Until the year 2050.

Cyprus, with the right planning can make the most of its energy potential, by being transformed into a producer-state. It can export electricity using appropriate electricity interconnections, such as the EuroAsia Interconnector and EuroAfrica Interconnector, so as to remove Cyprus' energy isolation. At the same time, Cyprus can become a hub for electricity transfer to and from the EU and to and from Israel and Egypt, while increasing our energy security. Hydrogen offers the opportunity to solve the problems of energy supply, climate change and air pollution facing the Southeastern Mediterranean countries. This entails the transformation of the existing polluting energy system of Cyprus and of the countries of the Southeastern Mediterranean into a sustainable energy system based on differentiated energy sources of higher 
energy efficiency with a long-term goal of turning the economy into a hydrogen economy to enhance cooperation and prosperity.

\section{Competing Interests}

Andreas Poullikkas is a member of the Editorial Board of the journal Green Energy and Sustainability. He was not involved in the journal's review of or decisions related to, this manuscript.

\section{References}

1. Poullikkas A. Introduction to power generation technologies. New York, USA: NOVA Science Publishers, Inc. 2009.

2. Poullikkas $A$. The cost of integration of renewable energy sources. Accountancy. 2010;101:100-101.

3. Velazquez Abad A, Dodds PE. Green hydrogen characterisation initiatives: Definitions, standards, guarantees of origin, and challenges. Energy Policy. 2020;138:111-300. DOI

4. Poullikkas A. Long-term Sustainable Energy Strategy: Cyprus's Energy Transition to Hydrogen Economy. Nicosia, Cyprus: Easy Conferences Ltd.; 2020. DOI

5. Ren X, Dong L, Xu D, Hu B. Challenges towards hydrogen economy in China. Int J Hydrogen Energ. 2020;45(59):34326-34345. DOI

6. Yáñez M, Ortiz A, Brunaud B, Grossmann IE, Ortiz I. The use of optimization tools for the Hydrogen Circular Economy. In: 29th European Symposium on Computer Aided Process Engineering. Vol. 46 of Computer Aided Chemical Engineering. Kiss AA, Zondervan E, Lakerveld R, Özkan L, Editors. Amsterdam, The Netherlands: Elsevier; 2019;1777-1782. DOI

7. Poullikkas A. The Cyprus Energy Future. Nicosia, Cyprus: Theopress Ltd.; 2009.

8. Road map to a US hydrogen economy. Fuel Cells Bull. 2020;11:12. DOI

9. Martinez-Burgos WJ, de Souza Candeo E, Pedroni Medeiros AB, Cesar de Carvalho J, Oliveira de Andrade Tanobe V, Soccol CR, et al. Hydrogen: Current advances and patented technologies of its renewable production. J Clean Prod. 2020; 124-170. DOI

10. Stygar M, Brylewski T. Towards a hydrogen economy in Poland. Int J Hydrogen Energ. 2013;38(1):1-9. DOI

11. Winter CJ. Into the hydrogen energy economy-milestones. Int J Hydrogen Energ. 2005;30(7):681-685. DOI 
12. Dou Y, Sun L, Ren J, Dong L. Chapter 10 - Opportunities and Future Challenges in Hydrogen Economy for Sustainable Development. Hydrogen Economy. 2017;277-305. DOI

13. Amoretti M. Towards a peer-to-peer hydrogen economy framework. Int J Hydrogen Energ. 2011;36(11):6376-6386. DOI

14. Poullikkas A. Sustainable Energy Development for Cyprus. Nicosia, Cyprus: Easy Conferences Ltd.; 2013.

15. Pinsky R, Sabharwall P, Hartvigsen J, O'Brien J. Comparative review of hydrogen production technologies for nuclear hybrid energy systems. Prog Nucl Energ. 2020;123:103-317. DOI

16. Taljan G, Fowler M, Cañizares C, Verbič G. Hydrogen storage for mixed wind - nuclear power plants in the context of a Hydrogen Economy. Int J Hydrogen Energ. 2008;33(17):4463-4475. DOI

17. Murray ML, Hugo Seymour E, Rogut J, Zechowska SW. Stakeholder perceptions towards the transition to a hydrogen economy in Poland. Int J Hydrogen Energ. 2008;33(1):20-27. DOI

18. Nikolaidis P, Poullikkas A. A comparative overview of hydrogen production processes. Renew Sust Energ Rev. 2017;67:597-611. DOI

19. Murray ML, Hugo Seymour E, Pimenta R. Towards a hydrogen economy in Portugal. Int J Hydrogen Energ. 2007;32(15):3223-3229. DOI

20. Poullikkas A. Sustainable options for electric vehicle technologies. Renew Sust Energ Rev. 2015;41:1277-1287.DOI

21. Poullikkas A. Optimization analysis for pumped energy storage systems in small isolated power systems. J. Power Technol. 2013;93:78-89.

22. Poullikkas A. Technology prospects of wave power systems. Electron J Energ Environ Environment. 2014;2:47-69.

23. Poullikkas A. A comparative overview of large-scale battery systems for electricity storage. Renew Sust Energ Rev. 2013;27:778-788. DOI

24. Singh R, Singh M, Gautam S. Hydrogen economy, energy, and liquid organic carriers for its mobility. Materials Today: Proceedings. 2020;46;5420-5427. DOI

25. Moreno-Benito M, Agnolucci P, McDowall W, Papageorgiou LG. Towards a sustainable hydrogen economy: Role of carbon price for achieving GHG emission targets. In: Kravanja Z, Bogataj M, editors. 26th European Symposium on Computer Aided Process Engineering. vol. 38 of Computer Aided Chemical Engineering. Elsevier; 2016;1015-1020. DOI

26. Poullikkas A. Renewable energy: Economics, emerging technologies and global practices. New York, USA: NOVA Science Publishers, Inc.; 2013. 
27. Zhang G, Zhang J, Xie T. A solution to renewable hydrogen economy for fuel cell buses - A case study for Zhangjiakou in North China. Int J Hydrogen Energ. 2020;45(29):14603-14613. DOI

28. Bossel U. Chapter 19 - Hydrogen economy: What future? In: Iulianelli A, Basile A, editors. Current Trends and Future Developments on (Bio-) Membranes. Elsevier; 2020;421-451. DOI

29. Abe JO, Popoola API, Ajenifuja E, Popoola OM. Hydrogen energy, economy and storage: Review and recommendation. Int J Hydrogen Energ. 2019;44(29):15072-15086. DOI

30. Brey JJ, Brey R, Carazo AF, Contreras I, Hernández-Díaz AG, Castro A. Planning the transition to a hydrogen economy in Spain. Int J Hydrogen Energ. 2007;32(10-11):1339-1346. DOI

31. Cloete S, Ruhnau O, Hirth L. On capital utilization in the hydrogen economy: The quest to minimize idle capacity in renewables-rich energy systems. Int J Hydrogen Energ. 2021;46(1):169-188. DOI

32. Iordache I, Gheorghe AV, Iordache M. Towards a hydrogen economy in Romania: Statistics, technical and scientific general aspects. Int J Hydrogen Energ. 2013;38(28):12231-12240. DOI

33. Logan KG, Nelson JD, McLellan BC, Hastings A. Electric and hydrogen rail: Potential contribution to net zero in the UK. Transp Res D Transp Environ. 2020;87:102-123. DOI

34. Kazi MK, Eljack F, El-Halwagi MM, Haouari M. Green hydrogen for industrial sector decarbonization: Costs and impacts on hydrogen economy in Qatar. Comput Chem. Eng. 2020;145:107144. DOI

35. Koyuncu I, Yilmaz C, Alcin M, Tuna M. Design and implementation of hydrogen economy using artificial neural network on field programmable gate array. Int J Hydrogen Energ. 2020;45(41):20709-20720. DOI

Cite this article: Poullikkas A. Perspectives for the development of energy strategies - Challenges towards a hydrogen economy in Cyprus. Green Energy Sustain 2021, 1(2), 0004.

https://doi.org/10.47248/HKOD902101020004 